\title{
The expression of ARHI in pT2a and pT2b stage gastric cancer and its clinical significance
}

\author{
WEI WANG $^{1}$, XIAN-MIN BU ${ }^{3}$, JIAN WANG ${ }^{2}$, NING ZHANG $^{1}$ and CHENG-HAI ZHAO ${ }^{1}$ \\ Departments of ${ }^{1}$ Pathophysiology, ${ }^{2}$ Microbiology and Parasitology, College of Basic Medical Science, \\ China Medical University, Shenyang 110001; ${ }^{3}$ Department of General Surgery, Shengjing \\ Hospital of China Medical University, Shenyang 110001, P.R. China
}

Received December 29, 2011; Accepted January 26, 2012

DOI: $10.3892 /$ or.2012.1727

\begin{abstract}
ARHI is a novel tumor suppressor gene located on chromosome 1p31. Downregulation of ARHI expression has been detected in many types of cancer. However, the effects of ARHI in gastric cancer remain unclear. The aim of this study was to identify the relationship between ARHI expression and gastric cancer clinicopathological features. In this study, 81 pT2 stage gastric cancer specimens were subclassified by pT2a and pT2b stage. ARHI mRNA and protein levels were evaluated by real-time PCR and western blot analysis, respectively. Methylation plays an important role in suppressor gene silencing. We utilized methylation-specific PCR to identify the status of $\mathrm{CpG}$ islands in the ARHI gene. We used immunohistochemistry to determine the expression of the protein and analyzed clinicopathological features. The levels of ARHI mRNA in gastric cancer were lower compared to normal tissues $(\mathrm{P}<0.01)$. Similarly, the levels of ARHI protein in the cancer specimens were lower $(\mathrm{P}<0.05)$. DNA hypermethylation was identified in $79.1 \%$ of gastric cancer specimens without ARHI expression. Immunohistochemistry results were significantly correlated with the pT 2 category $(\mathrm{P}<0.05)$. The cumulative survival rate of patients with ARHI expression was significantly higher compared to those without ARHI expression $(\mathrm{P}<0.05)$. ARHI as a suppressor is not only an important factor in the pathogenesis of gastric cancer, but also a potential factor for tumor aggravation. ARHI expression in gastric cancer can be employed to indicate favorable prognosis for the disease.
\end{abstract}

\section{Introduction}

ARHI/NOEY2, a novel tumor suppressor gene, is located on chromosome 1p31 $(1,2)$. It encodes a small GTPase with $60 \%$

Correspondence to: Dr Cheng-Hai Zhao, Department of Pathophysiology, College of Basic Medicine, China Medical University, Shenyang 110001, P.R. China

E-mail: cmu_chenghai@163.com

Key words: ARHI gene, gastric cancer, clinicopathological features, hypermethylation, immunohistochemistry homology to Ras and Rap (1). The product can bind to GTP but it does not function similarly to Ras and Rap (3). However, ARHI can inhibit cancer cell proliferation and induce apoptosis $(3,4)$. DNA methylation can contribute to human oncogenesis. Many loss-of-function mutations in tumor suppressor genes occur by methylation of $\mathrm{CpG}$ islands in the promoter region, such as in the retinoblastoma gene (5) and in p16 (6). Previous research has shown that ARHI is downregulated in pancreatic (7), ovarian (8), breast (9), hepatocellular (10) and follicular thyroid cancers (11). Loss of ARHI expression has been associated with hypermethylation of the promoter region. As shown in the ideogram (Fig. 1), there are three $\mathrm{CpG}$ islands in the ARHI gene. $\mathrm{CpG}$ islands I and II are located in the promoter region, whereas $\mathrm{CpG}$ island III is located in the coding region (12).

According to GLOBOCAN 2008 statistics, gastric cancer is the fourth most common cancer and the second-leading cause of cancer-related deaths worldwide (13). In China, gastric cancer currently ranks the third among most common cancers, and will remain a significant cancer burden during the next decade (14). The number of metastatic lymph nodes ( $\mathrm{N}$ stage) and the depth of the primary tumor (T stage) are two important categories for gastric cancer $(15,16)$. In the sixth edition of the International Union Against Cancer (UICC)/American Joint Committee on Cancer (AJCC) staging manual, the pT2 category was subclassified into pT2a and pT2b based on the depth of tumor invasion (17). pT2a and pT2b, respectively, represent the tumor invaded to the muscularis propria (MP) and subserosa (SS) layer (18-20).

To the best of our knowledge, no studies have investigated whether ARHI/NOEY2 mRNA levels in gastric cancer tissues associate with ARHI promoter methylation. In our studies, gastric cancer specimens were classified by $\mathrm{pT} 2 \mathrm{a}$ and $\mathrm{pT} 2 \mathrm{~b}$ and the levels of ARHI mRNA and protein in the two subtypes were compared. Simultaneously, we evaluated the methylation status of ARHI in normal and malignant tissues to investigate the molecular basis for ARHI protein underexpression. Finally, we used immunohistochemistry to determine the expression of the protein and analyzed the clinicopathological features of patients.

\section{Patients and methods}

Subjects. Surgical specimens of 81 pT2 stage gastric cancers were obtained from the Department of General Surgery, 
Shengjing Hospital of China Medical University between January 2006 and May 2011. None of the patients underwent radiotherapy or chemotherapy before operation. All patients gave their consent for the use of tumor tissues for clinical research and our university Ethics Committee approved the research protocols. The specimens were subclassified in pT2a and pT2b stage. Adjacent mucosa and primary tumors of all the cases were fixed in $4 \%$ formaldehyde solution, embedded in paraffin and cut into $4-\mu \mathrm{m}$ sections.

Quantitative real-time PCR. Total-RNA was extracted from specimens using TRIzol reagent (Invitrogen) according to the manufacturer's instructions. First-strand cDNAs were generated in reverse transcriptase reactions containing total-RNA, poly(dt) oligonucleotides, and SuperScript II reverse transcriptase (Invitrogen). cDNAs were then subjected to quantitative real-time PCR analysis. The ARHI primers used were, 5'-CAGCTGGTTTCTTACCACGTAT-3' (forward) and 5'-GC ACAAGTTCTCCCACACTTAG-3' (reverse). The GADPH primers used were, 5'-AGAAGGCTGGGGCTCATTTG-3' (forward) and 5'-AGGGGCCATCCACAGTCTTC-3' (reverse). Amplification of ARHI and GADPH was performed with 1 cycle at $95^{\circ} \mathrm{C}$ for $10 \mathrm{~min}$ and 40 cycles of $95^{\circ} \mathrm{C}$ for $15 \mathrm{sec}$ and $60^{\circ} \mathrm{C}$ for $60 \mathrm{sec}$.

Immunoblotting. Surgical specimens were lysed in ice-cold buffer containing $50 \mathrm{mM}$ Tris- $\mathrm{HCl}(\mathrm{pH} 7.4), 150 \mathrm{mM} \mathrm{NaCl}$, $1 \mathrm{mM}$ EDTA, $1 \%$ NP-40, $0.25 \%$ sodium deoxycholate, $1 \mathrm{mM}$ phenylmethylsulfonyl fluoride, a cocktail of protease inhibitors, and phosphatase inhibitors $(1 \mathrm{mM}$ sodium pyrophosphate, $10 \mathrm{mM} \mathrm{NaF}, 1 \mathrm{mM} \mathrm{Na} \mathrm{VO}_{4}$ ) and left on ice for $20 \mathrm{~min}$ before centrifuging at $12,000 \mathrm{x}$ g for $10 \mathrm{~min}$ at $4^{\circ} \mathrm{C}$ to remove insoluble material. The protein concentration was determined using the Bio-Rad protein assay reagent (Bio-Rad Laboratories, USA) and $60 \mu \mathrm{g}$ of total protein were electrophoresed on $10 \%$ SDS-PAGE denaturing gels and transferred to polyvinylidene difluoride membranes by electroblotting. Immunoblotting was performed using $1 \mu \mathrm{g} / \mathrm{ml}$ of goat polyclonal anti-ARHI (Darmstadt, Germany) overnight at $4^{\circ} \mathrm{C}$ in $5 \%$ skim milk and TBST (50 mM Tris- $\mathrm{HCl}, 750 \mathrm{mM} \mathrm{NaCl}$, $0.25 \%$ Tween-20). Following washing $(3 \times 5 \mathrm{~min})$ in TBST, the detection of the primary antibodies was performed using a 1:5,000 dilution of rabbit anti-goat IgG, HRP-linked antibody (Santa Cruz Biotechnology, Inc., Japan) for $2 \mathrm{~h}$ at room temperature followed by washing in TBST $(3 \times 5 \mathrm{~min})$. The immunoblots were developed in ECL chemiluminescence reagent (Takara, Japan) and autoradiography was performed to visualize the immunoreactive bands. As a control for protein loading, membranes were re-probed with a 1:5,000 dilution of a mouse monoclonal anti- $\beta$-actin antibody (Santa Cruz Biotechnology, Inc.).

Methylation-specific PCR (MSP). Genomic DNA was extracted from specimens using a TissueGen DNAkit(CW Biotechnology, China). Genomic DNA of $2 \mu \mathrm{g}$ was denatured with $0.2 \mathrm{M}$ $\mathrm{NaOH}$. Then, $10 \mathrm{mM}$ hydroquinone (Sigma) and $3 \mathrm{M}$ sodiumbisulfite (Sigma) were added and the solution was incubated at $55^{\circ} \mathrm{C}$ for $16 \mathrm{~h}$. DNA samples were then purified using a Wizard DNA purification resin (Promega). In this procedure unmethylated (but not methylated) cytosines can convert to uracil, which

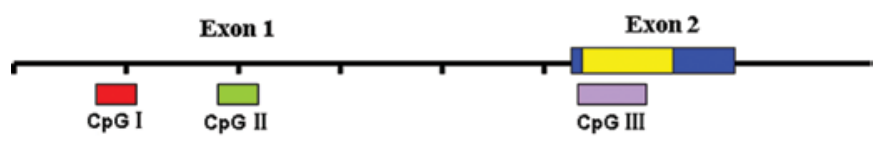

Figure 1. ARHI gene ideogram. Three $\mathrm{CpG}$ islands are found in the ARHI gene. $\mathrm{CpG}$ islands I and II are located in the promoter region, whereas $\mathrm{CpG}$ island III is located in the coding region.

is then converted to thymidine during subsequent PCR to identify sequence differences between methylated and unmethylated DNA. The modified DNA was used as a template for both the MSP and the unmethylated-specific PCR (USP). The primer sequences for the methylated ARHI CpG I gene were 5'-GCGGTGGTGCGTAGTTT-3' (sense) and 5'-AAAACG CCCCATCGAA-3' (antisense), and for the unmethylated alleles were 5'-GGTGTTTATAGGTAAGGGAGAAAGA-3' (sense) and 5'-CACAAAACACCCCATCAAAT-3' (antisense). The primer sequences for the methylated ARHI CpG II gene were 5'-CGTTTTGCGTTGGGTTAG-3' (sense) and 5'-ACCTTTCTCGAAAACACGAA-3' (antisense), and for the unmethylated alleles were 5'-TTGTGTTGTTTTGTGTT GGG-3' (sense) and 5'-CAAAAACTCACTCCTCCACAAT-3' (antisense). The primer sequences for the methylated ARHI CpG III gene were 5'-TAGAAGTTGTTGAAGCGGTTG-3' (sense) and 5'-CGATTACCGTCGCCACT-3' (antisense), and for the unmethylated alleles were 5'-TGTTGGTGTGGGG AAAAG-3' (sense) and 5'-AAAACACAATTACCATCAC CACT- 3 ' (antisense). The PCR products were separated on $2 \%$ agarose gel with ethidium bromide and visualized under UV illumination.

Immunohistochemical staining (IHC). Immunohistochemistry was used to detect the expression of ARHI protein in gastric cancer. The study population included 81 patients. Fortyseven $(58.1 \%)$ were male and $34(41.9 \%)$ female, and the minimum and maximum ages were 21 and 87 years, with a mean of $47.8 \pm 2.4$ years. Immunohistochemical staining was performed on $4-\mu \mathrm{m}$ sections obtained from formalin-fixed, paraffin-embedded blocks. Endogenous peroxidase activity was blocked with $3 \%$ hydrogen peroxide for $30 \mathrm{~min}$. Antigen retrieval was carried out in citrate buffer $(10 \mathrm{mM}, \mathrm{pH}$ 6.0) for $30 \mathrm{~min}$ at $95^{\circ} \mathrm{C}$ in a pressure cooker. Polyclonal antibodies used were anti-ARHI (Darmstadt) antibodies at 1:500 dilution and incubation was performed at $4^{\circ} \mathrm{C}$ overnight. Afterward, sections were incubated with a biotinylated secondary antibody and then exposed to a streptavidin complex (HRP). Positive reactions were visualized with 3,3'-diaminobenzidine tetrahydrochloride (DAB, Sigma), followed by counterstaining with hematoxylin. Normal tissue was used as a positive control. Sections treated without primary antibodies were used as negative controls. The positive percentage of counted cells was graded semi-quantitatively according to a four-tier scoring system: negative (-), $0-5 \%$; weakly positive $(+), 6-25 \%$; moderately positive (++), 26-50\%; and strongly positive (+++), 51-100\%.

Statistical analysis. Data were analyzed by GraphPad Prism 5. Chi-square analysis was used to test the difference of hypermethylation cases in each group. The Spearman correlation 
A
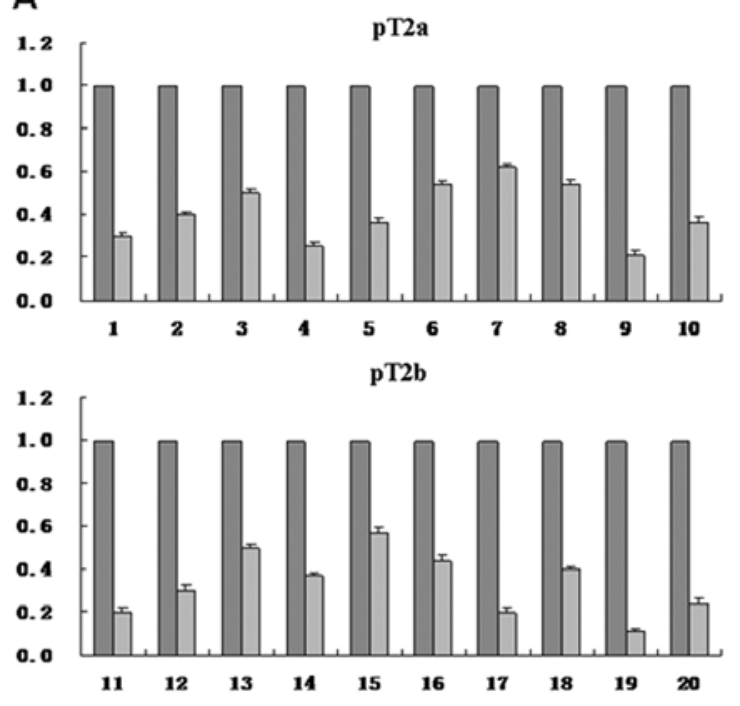

B

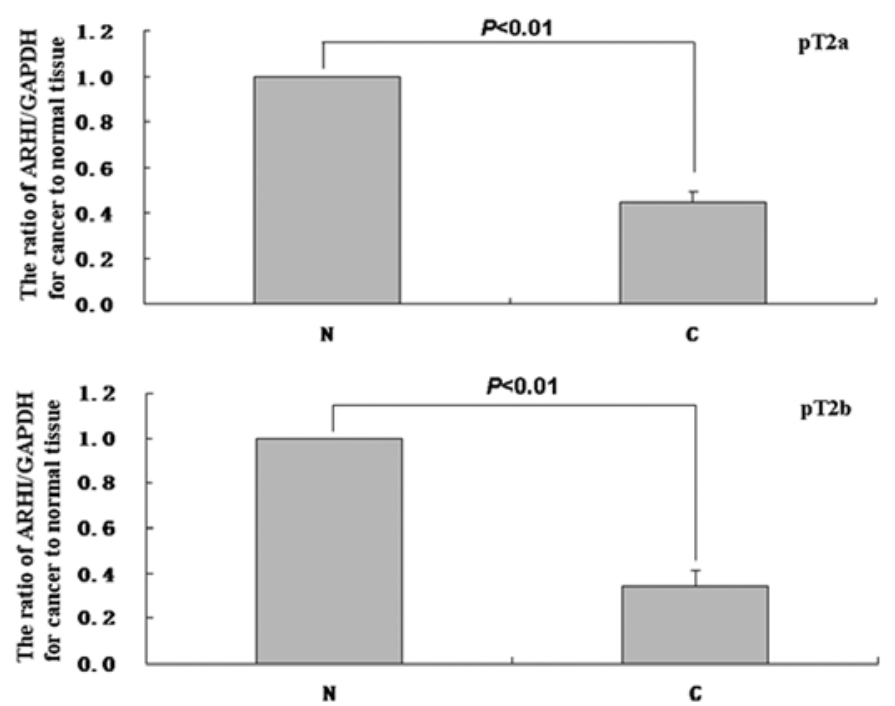

Figure 2. (A) Real-time PCR analysis of ARHI was carried out in pT2a and pT2b stage gastric cancers and respective adjacent noncancerous tissues. For each sample, the relative mRNA level of ARHI was normalized based on that of GAPDH. (B) The histogram demonstrates that the differences were statistically significant $(\mathrm{P}<0.01)$.

A
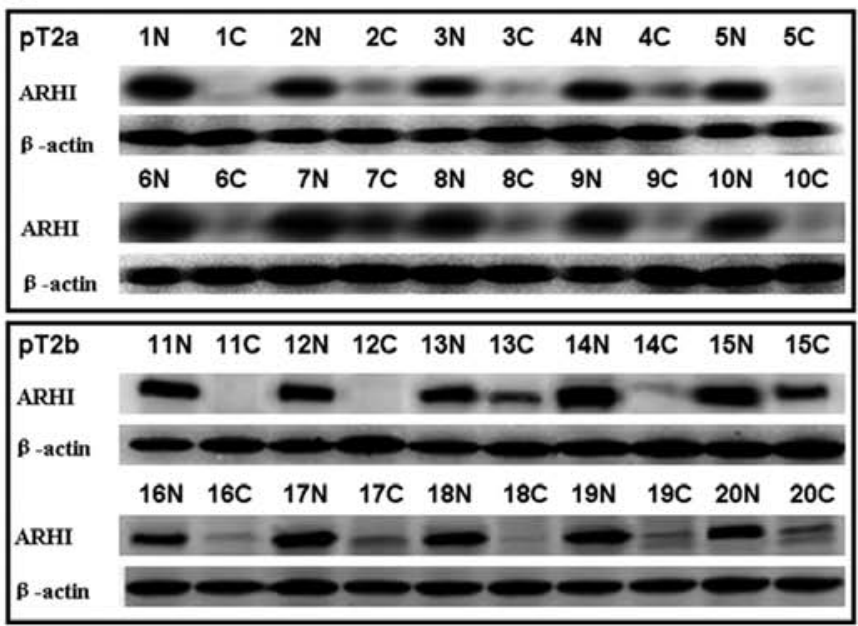

B
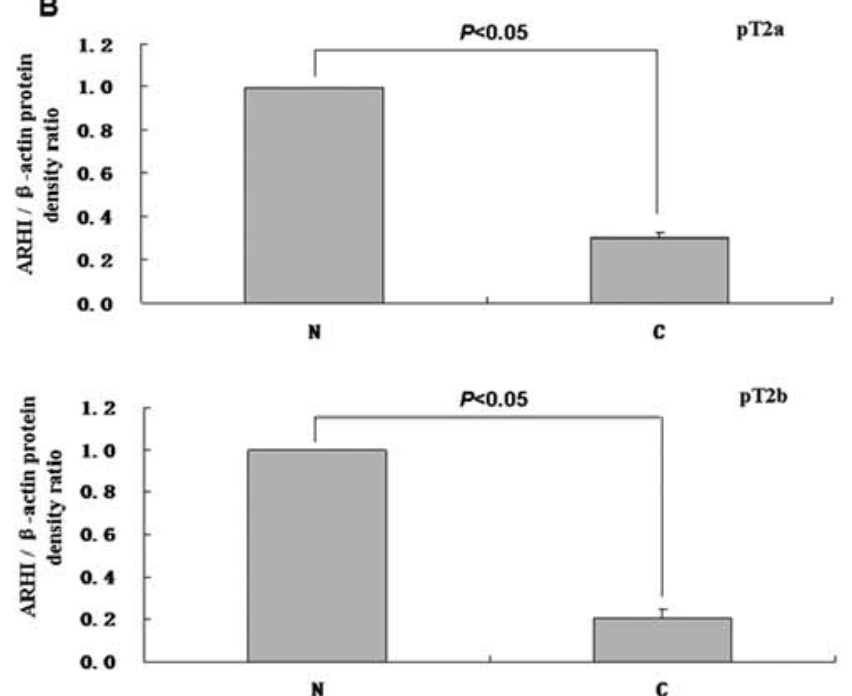

Figure 3. (A) ARHI protein levels measured by western blot analysis. $\beta$-actin was used as an internal control. (B) The histogram demonstrates that the differences were statistically significant $(\mathrm{P}<0.05)$.

test was uesd to analyze the rank data. Kaplan-Meier survival plots were generated and comparisons between survival curves were conducted with the log-rank statistic. P-values $<0.05$ were considered statistically significant.

\section{Results}

ARHI expression is reduced in gastric cancer. We compared ARHI expression in gastric cancer specimens from 81 patients with normal tissues (Fig. 2A). The results showed statistically significant differences $(\mathrm{P}<0.05)$ (Fig. 2B). Next, we evaluated the level of ARHI mRNA. As shown in Fig. 3A, the level of ARHI mRNA in cancers was lower than in normal tissues. The results were statistically significant $(\mathrm{P}<0.01)$ (Fig. 3B). The protein and mRNA were levels in accordance with each other. Representative examples 1-10 belong to pT2a and 11-20 to pT2b.

Reduced ARHI expression is associated with ARHI promoter methylation. To elucidate the methylation statuses, tumor samples were examined by MSP. Although $79.1 \%$ cases lacked ARHI expression associated with hypermethylation in different $\mathrm{CpG}$ islands, we observed seven types of methylation statuses including hypermethylation only in $\mathrm{CpG}$ islands I, II or III, hypermethylation in CpG islands I and II, CpG islands II and III, CpG islands I and III and hypermethylation in all CpG islands. Representative examples are illustrated in Fig. 4. Methylation statuses of 81 cases of gastric cancer are shown in Table I. There was a high frequency of ARHI methylation $(79.1 \%)$ in gastric cancers. The relationship between ARHI gene 
Table I. Methylation status of the 81 cases of gastric cancer.

\begin{tabular}{lrr}
\hline Methylation & $\mathrm{N}$ & $(\%)$ \\
\hline CpG island I & 5 & 6.3 \\
CpG island II & 7 & 8.7 \\
CpG island III & 9 & 11.1 \\
CpG island I and CpG island II & 13 & 16.0 \\
CpG island I and CpG island III & 10 & 12.3 \\
CpG island II and CpG island III & 11 & 13.6 \\
All CpG islands & 9 & 11.1 \\
No methylation & 17 & 20.9 \\
\hline
\end{tabular}

mutations and clinicopathological features of gastric cancer is listed in Table II. The results reveal that ARHI methylation was not correlated with patient ages, differentiation, lymphatic invasion, venous invasion, lymph node metastasis and tumor size $(\mathrm{P}>0.05)$ but related with pT2 category $(\mathrm{P}<0.05)$.

Correlation between ARHI expression and clinicopathological features in gastric cancer. The immunostaining for ARHI

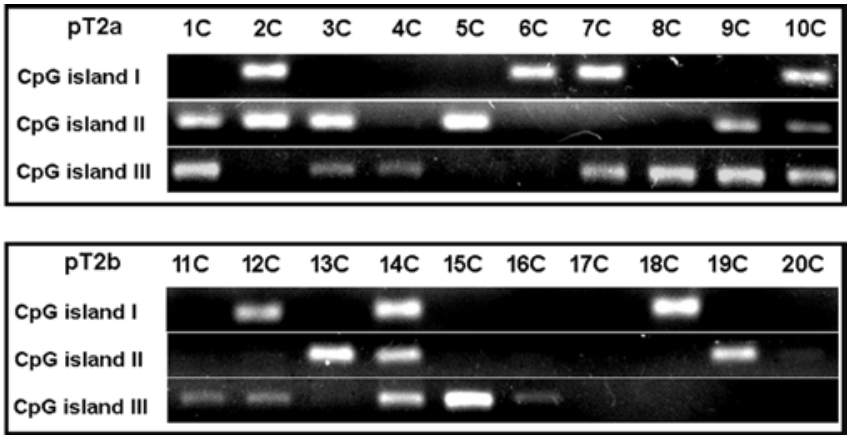

Figure 4. Aberrant methylation of ARHI CpG islands in gastric cancers. In the representative examples, hypermethylation of $\mathrm{CpG}$ island I was identified in $6 \mathrm{C}$ and $18 \mathrm{C}$, of $\mathrm{CpG}$ island II in 5C, $13 \mathrm{C}$ and $19 \mathrm{C}$, of $\mathrm{CpG}$ island III in $4 \mathrm{C}, 8 \mathrm{C}, 11 \mathrm{C}$, $15 \mathrm{C}$ and $16 \mathrm{C} .2 \mathrm{C}$ had hypermethylation of $\mathrm{CpG}$ island $\mathrm{I}$ and $\mathrm{CpG}$ island $\mathrm{II}, 7 \mathrm{C}$, $10 \mathrm{C}, 12 \mathrm{C}$ had hypermethylation of $\mathrm{CpG}$ island $\mathrm{I}$ and $\mathrm{CpG}$ island $\mathrm{III}, 1 \mathrm{C}, 3 \mathrm{C}$ and 9C had hypermethylation of $\mathrm{CpG}$ island II and $\mathrm{CpG}$ island III. $14 \mathrm{C}$ had partial methylation of all three $\mathrm{CpG}$ islands. $17 \mathrm{C}$ and $20 \mathrm{C}$ showed no methylation.

was only localized in the cytoplasm. ARHI protein was highly expressed in the non-tumor parts of the specimens (Fig. 5). We then analyzed the potential relationship between the expression of ARHI and the clinicopathological characteristics of

Table II. Comparison between methylation of the ARHI gene and clinicopathological data.

\begin{tabular}{|c|c|c|c|c|c|}
\hline Clinicopathological features & $\mathrm{N}$ & $\begin{array}{l}\text { Hypermethylation } \\
\text { cases }\end{array}$ & $\begin{array}{c}\text { Hypermethylation } \\
\text { rate } \%\end{array}$ & $\chi^{2}$ value & P-value \\
\hline Gender & & & & 0.005 & 0.200 \\
\hline Female & 34 & 27 & 79.4 & & \\
\hline Male & 47 & 37 & 78.7 & & \\
\hline Age (years) & & & & 2.140 & 0.083 \\
\hline$<65$ & 35 & 25 & 71.4 & & \\
\hline$\geq 65$ & 46 & 39 & 84.8 & & \\
\hline Differentiation & & & & 1.484 & 0.110 \\
\hline Differentiated & 53 & 44 & 83.0 & & \\
\hline Unidifferentiated & 28 & 20 & 71.4 & & \\
\hline Lymphatic invasion & & & & 0.715 & 0.162 \\
\hline- & 50 & 38 & 76.0 & & \\
\hline+ & 31 & 26 & 83.8 & & \\
\hline Venous invasion & & & & 0.145 & 0.251 \\
\hline- & 64 & 50 & 78.1 & & \\
\hline+ & 17 & 14 & 82.3 & & \\
\hline Lymph node metastasis & & & & 0.010 & 0.212 \\
\hline- & 42 & 33 & 78.5 & & \\
\hline+ & 39 & 31 & 79.5 & & \\
\hline Tumor size & & & & 3.135 & 0.053 \\
\hline$<4 \mathrm{~cm}$ & 57 & 48 & 84.2 & & \\
\hline$\geq 4 \mathrm{~cm}$ & 24 & 16 & 66.7 & & \\
\hline pT2 category & & & & 5.380 & 0.022 \\
\hline $\mathrm{pT} 2 \mathrm{a}$ & 37 & 25 & 67.6 & & \\
\hline $\mathrm{pT} 2 \mathrm{~b}$ & 44 & 39 & 88.6 & & \\
\hline
\end{tabular}

$\chi^{2}$ value, Chi-square distribution. 


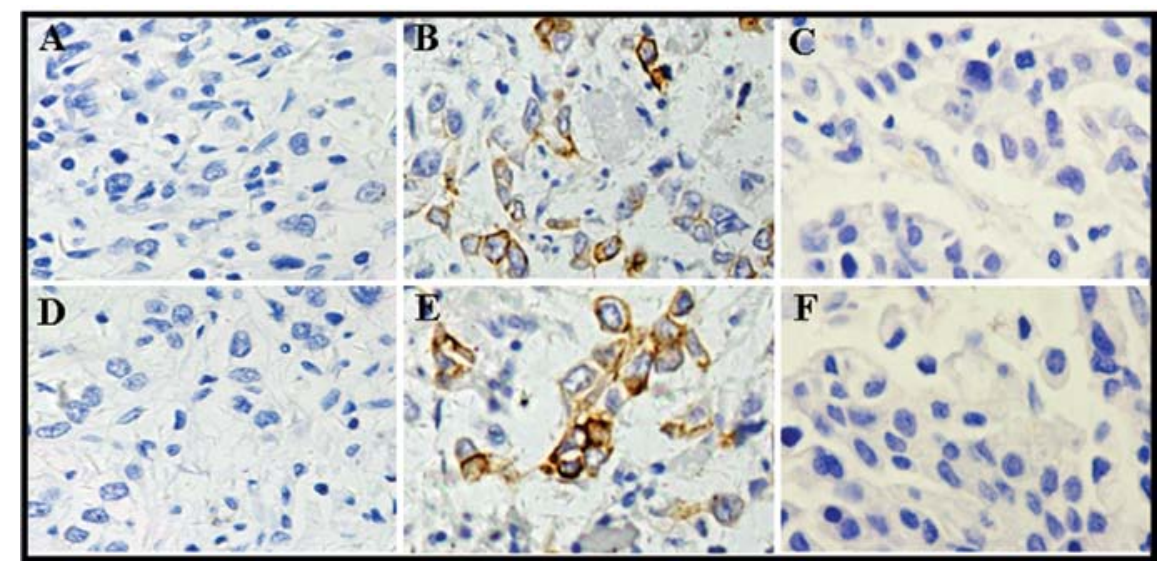

Figure 5. Representative results of two-paired of gastric cancer and corresponding noncancerous tissue specimens by immunohistochemical staining with anti-ARHI antibody. (A) pT2a stage cancer (B) pT2a paired noncancerous tissue (D) pT2b stage cancer (E) pT2b paired noncancerous tissue. (C and F) negative controls. ARHI was stained brown with granules and localized to the cytoplasm. The nuclei were counterstained with hematoxylin.

A

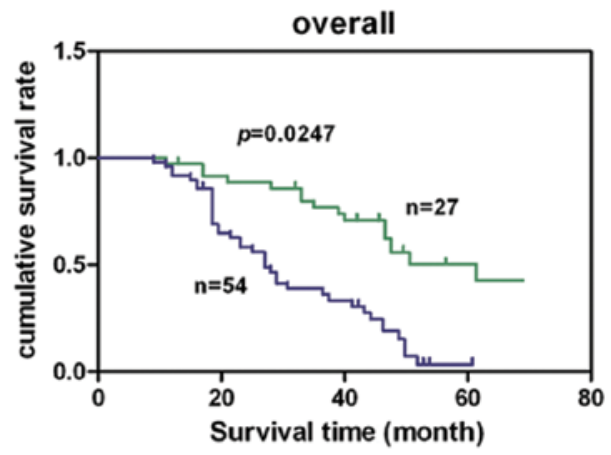

ARHI expression

- positive

+ positive-censored

- negative

+ negative-censored
B

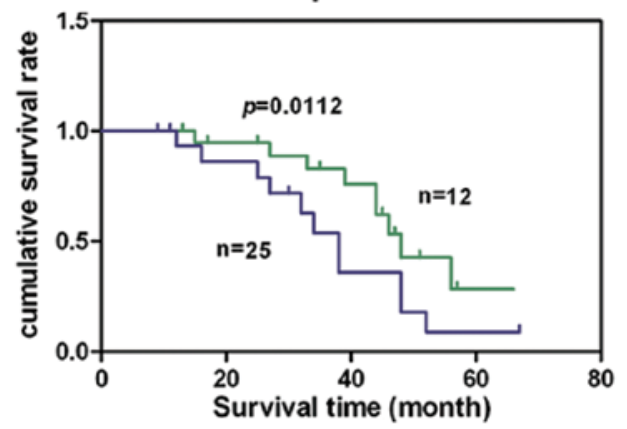

C

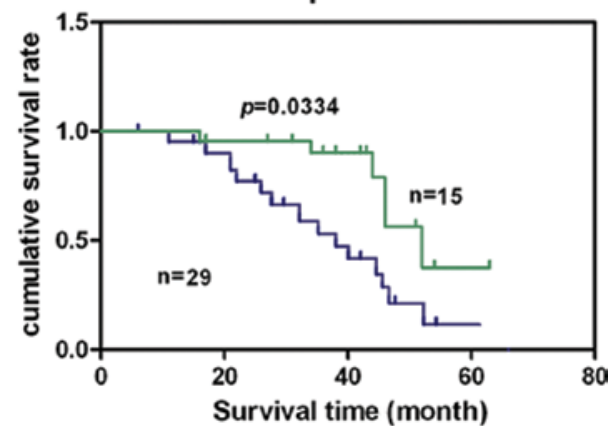

Figure 6. Correlation between ARHI status and prognosis of the gastric cancer patients. Kaplan-Meier curves for cumulative survival rate of patients with gastric cancer according to ARHI expression in (A) all specimens, (B) pT2a stage and (C) pT2b stage gastric cancer specimens.

these patients. The results are summarized in Table III. No correlation was found with sex, ages, differentiation, lymphatic invasion, venous invasion, lymph node metastasis and tumor size $(\mathrm{P}>0.05)$. However ARHI expression was significantly associated with pT2 category $(\mathrm{P}<0.05)$.

Univariate and multivariate survival analysis. Follow-up information was available on 81 patients with gastric cancer for periods ranging from 0.2 months to 5 years (median, 34 months). Survival curves according to ARHI expression for gastric cancer are shown in Fig. 6. Univariate analysis using the Kaplan-Meier method was used to assess the cumulative survival rate of patients with ARHI expression, which was determined to be notably higher than the ones without ARHI expression $(\mathrm{P}<0.05)$ (Fig. 6).

\section{Discussion}

ARHI is a maternally imprinted, small Ras-related GTPase gene that maps to $1 \mathrm{p} 31$ and has been suggested to function as a tumor suppressor gene (1-3). Despite extensive study of ARHI function in many types of cancer, relatively little is known about its role in gastric cancer (6-10). According to the depth of tumor invasion, our specimens were subclassified into pT2a and pT2b stage (17). In this study, we first report that the level of ARHI mRNA was found to be lower in gastric 
Table III. Relationship between ARHI expression and clinicopathological parameters of gastric cancer.

\begin{tabular}{|c|c|c|c|c|c|c|c|c|}
\hline \multirow[b]{2}{*}{ Clinicopathological features } & \multirow[b]{2}{*}{$\mathrm{N}$} & \multicolumn{4}{|c|}{ ARHI expression } & \multirow[b]{2}{*}{$\mathrm{PR}(\%)$} & \multirow[b]{2}{*}{ Rs } & \multirow[b]{2}{*}{ P-value } \\
\hline & & - & + & ++ & +++ & & & \\
\hline Gender & & & & & & & 0.230 & 0.738 \\
\hline Female & 34 & 25 & 6 & 1 & 2 & 26.5 & & \\
\hline Male & 47 & 29 & 8 & 6 & 4 & 38.3 & & \\
\hline Age (years) & & & & & & & 0.055 & 0.452 \\
\hline$<65$ & 35 & 24 & 5 & 2 & 4 & 45.8 & & \\
\hline$\geq 65$ & 46 & 30 & 5 & 6 & 5 & 50.0 & & \\
\hline Differentiation & & & & & & & 0.032 & 0.612 \\
\hline Differentiated & 53 & 38 & 5 & 6 & 4 & 37.7 & & \\
\hline Unidifferentiated & 28 & 16 & 5 & 4 & 3 & 34.8 & & \\
\hline Lymphatic invasion & & & & & & & 0.251 & 0.103 \\
\hline - & 50 & 34 & 6 & 7 & 3 & 32.0 & & \\
\hline+ & 31 & 20 & 5 & 4 & 2 & 35.5 & & \\
\hline Venous invasion & & & & & & & 0.091 & 0.332 \\
\hline - & 64 & 48 & 9 & 6 & 1 & 25.0 & & \\
\hline+ & 17 & 6 & 7 & 3 & 1 & 64.7 & & \\
\hline Lymph node metastasis & & & & & & & 0.033 & 0.652 \\
\hline- & 42 & 29 & 6 & 4 & 3 & 30.9 & & \\
\hline+ & 39 & 25 & 7 & 5 & 2 & 35.8 & & \\
\hline Tumor size & & & & & & & 0.124 & 0.427 \\
\hline$<4 \mathrm{~cm}$ & 57 & 43 & 6 & 5 & 3 & 24.6 & & \\
\hline$\geq 4 \mathrm{~cm}$ & 24 & 11 & 3 & 8 & 2 & 54.2 & & \\
\hline pT2 category & & & & & & & 0.225 & 0.023 \\
\hline pT2a & 37 & 25 & 6 & 4 & 2 & 32.4 & & \\
\hline pT2b & 44 & 29 & 5 & 5 & 5 & 34.1 & & \\
\hline
\end{tabular}

PR, positive rate; Rs, Spearman correlation coefficient.

cancers than in adjacent noncancerous tissues regardless of pT $2 \mathrm{a}$ and pT2b stage. The results were consistent with the level of ARHI protein. However, there was no obvious difference between pT2a and pT2b stage cancers. This indicated that ARHI may be an important factor in the pathogenesis of gastric cancer.

In order to further explore the cause of the downregulation of ARHI in gastric cancers, MSP was carried out to analyze the status of $\mathrm{CpG}$ islands of ARHI in pT2a and pT2b stage cancers. Loss of ARHI expression occurring through DNA methylation has been demonstrated in breast and ovarian cancer (11-21). We designed three pairs of primers to detect three $\mathrm{CpG}$ islands of the ARHI gene. As shown in our results, non-methylation of $\mathrm{CpG}$ islands was observed only in 17 cases and complete or partial methylation of three islands in the other 64 cases. Yuan et al (12) have identified three types of methylation in breast cancer. However, we found seven types of methylation according to the different $\mathrm{CpG}$ islands. We hypothesized that this discrepancy was caused by tissue specificity. Further study will be carried out to verify our hypothesis. It has been demonstrated that $\mathrm{CpG}$ islands I and II are located in the promoter region and $\mathrm{CpG}$ island III is located in the coding region (12). Generally, aberrant methylation status of $\mathrm{CpG}$ islands, often located in the promoter regions of genes, serves as an important mechanism for the inactivation of tumor suppressor genes in cancers (22-24). Similarly, in our studies, downregulation of ARHI was mainly associated with methylation in $\mathrm{CpG}$ islands I or II. Notably, methylation of $\mathrm{CpG}$ island III also led to underexpression of ARHI. The mechanism remains unclear. In further analyses, we also found that methylation of the ARHI gene was correlated with pT 2 category. To the best of our knowledge, this is the first study to analyze the methylation of the ARHI gene and the correlation with clinicopathological data. Our results indicate that methylation of the ARHI gene may contribute to the pathogenesis and aggravation of gastric cancer.

We then utilized immunohistochemistry to detect the level of ARHI in gastric cancer and in adjacent normal tissue. As shown in the representative results, ARHI is more highly expressed in normal tissues. Our data are consistent with the report of Lu et al (7) who detected ARHI in pancreatic cancer. Additionally, our results also showed that ARHI was only localized in the cytoplasm. Dalai et al (25) using logistic regression analysis identified a significant correlation between 
ARHI expression and pancreatic endocrine tumor differentiation. However, our results showed no association between ARHI expression and carcinoma differentiation. It was only correlated with pT2 category. The discrepancies might be largely caused by different tissues and statistical methods. To further clarify the clinicopathological significance, the correlation between ARHI expression and survival of 81 patients was assessed. Patients with lower ARHI expression showed a significantly higher hazard ratio for disease pathogenesis and progression compared with those with normal ARHI expression. Regardless of pT2 category, same results were obtained in pT2a and pT2b stage patients. This is agreement with the results of Dalai et al (25) in pancreatic cancer.

In summary, downregulation of ARHI may play an important role both in the pathogenesis and aggravation of gastric cancer. ARHI gene $\mathrm{CpG}$ island methylation is a potential molecular basis of its downregulation. ARHI expression seems to be a favorable prognostic factor for the disease.

\section{Acknowledgements}

This study was supported by the Natural Science Foundation of the Liaoning province (no. 20092125). We thank Dr Yu Li for technical assistance.

\section{References}

1. Yu Y, Xu F, Peng H, et al: NOEY2 (ARHI), an imprinted putative tumor suppressor gene in ovarian and breast carcinomas. Proc Natl Acad Sci USA 96: 214-219, 1999.

2. Peng H, Xu F, Pershad R, et al: ARHI is the center of allelic deletion on chromosome 1p31 in ovarian and breast cancers. Int J Cancer 86: 690-694, 2000.

3. Luo RZ, Fang X, Marquez R, et al: ARHI is a Ras-related small G-protein with a novel N-terminal extension that inhibits growth of ovarian and breast cancers. Oncogene 22: 2897-2909, 2003.

4. Bao JJ, Le XF, Wang RY, et al: Reexpression of the tumor suppressor gene ARHI induces apoptosis in ovarian and breast cancer cells through a caspase-independent calpain-dependent pathway. Cancer Res 62: 7264-7272, 2002.

5. Ohtani-Fujita N, Dryja TP, Rapaport JM, et al: Hypermethylation in the retinoblastoma gene is associated with unilateral, sporadic retinoblastoma. Cancer Genet Cytogenet 98: 43-49, 1997.

6. Dong SM, Kim HS, Rha SH, et al: Promoter hypermethylation of multiple genes in carcinoma of the uterine cervix. Clin Cancer Res 7: 1982-1986, 2001.

7. $\mathrm{Lu} \mathrm{ZH,} \mathrm{Chen} \mathrm{J,} \mathrm{Gu} \mathrm{LJ,} \mathrm{et} \mathrm{al:} \mathrm{ARHI} \mathrm{mRNA} \mathrm{and} \mathrm{protein} \mathrm{expres-}$ sion in pancreatic cancers. Zhongguo Yi Xue Ke Xue Yuan Xue Bao 23: 324-327, 2001 (In Chinese).
8. Rosen DG, Wang L, Jain AN, et al: Expression of the tumor suppressor gene ARHI in epithelial ovarian cancer is associated with increased expression of p21WAF1/CIP1 and prolonged progression-free survival. Clin Cancer Res 10: 6559-6566, 2004.

9. Wang L, Hoque A, Luo RZ, et al: Loss of the expression of the tumor suppressor gene ARHI is associated with progression of breast cancer. Clin Cancer Res 9: 3660-3666, 2003.

10. Huang J, Lin Y, Li L, et al: ARHI, as a novel suppressor of cell growth and downregulated in human hepatocellular carcinoma, could contribute to hepatocarcinogenesis. Mol Carcinog 48: 130-140, 2009.

11. Weber F, Aldred MA, Morrison CD, et al: Silencing of the maternally imprinted tumor suppressor ARHI contributes to follicular thyroid carcinogenesis. J Clin Endocrinol Metab 90: 1149-1155, 2005.

12. Yuan J, Luo RZ, Fujii S, et al: Aberrant methylation and silencing of ARHI, an imprinted tumor suppressor gene in which the function is lost in breast cancers. Cancer Res 63: 4174-4180, 2003.

13. Ferlay J, Shin HR, Bray F, et al: GLOBOCAN 2008 v1.2, Cancer Incidence and Mortality Worldwide: IARC CancerBase No.10, IARC, Lyon, 2010.

14. Yang L: Incidence and mortality of gastric cancer in China. World J Gastroenterol 12: 17-20, 2006.

15. Hohenberger P and Gretschel S: Gastric cancer. Lancet 362: 305-315, 2003.

16. Dicken BJ, Bigam DL, Cass C, et al: Gastric adenocarcinoma: review and considerations for future directions. Ann Surg 241: 27-39, 2005.

17. Greene FL, Page DL, Fleming ID, et al: AJCC Cancer Staging Manual. 6th edition. Springer-Verlag, New York, 2002.

18. Park do J, Kong SH, Lee HJ, et al: Subclassification of pT2 gastric adenocarcinoma according to depth of invasion (pT2a vs. pT2b) and lymph node status (pN). Surgery 141: 757-763, 2007.

19. Okuno K, Shigeoka H, Tanaka A, et al: Clinicopathological evaluation of T2-gastric cancer among age groups. Hepatogastroenterology 47: 1180-1182, 2000.

20. Isozaki H, Fujii K, Nomura E, et al: Prognostic factors of advanced gastric carcinoma without serosal invasion (pT2 gastric carcinoma). Hepatogastroenterology 46: 2669-2672, 1999.

21. Fujii S, Luo RZ, Yuan J, et al: Reactivation of the silenced and imprinted alleles of ARHI is associated with increased histone $\mathrm{H} 3$ acetylation and decreased histone $\mathrm{H} 3$ lysine 9 methylation. Hum Mol Genet 12: 1791-1800, 2003.

22. Herman JG and Baylin SB: Gene silencing in cancer in association with promoter hypermethylation. N Engl J Med 349: 2042-2054, 2003.

23. Herman JG, Merlo A, Mao L, et al: Inactivation of the CDKN2/ p16/MTS1 gene is frequently associated with aberrant DNA methylation in all common human cancers. Cancer Res 55: 4525-4530, 1995.

24. Merlo A, Herman JG, Mao L, et al: 5'CpG island methylation is associated with transcriptional silencing of the tumour suppressor p16/CDKN2/MTS1 in human cancers. Nat Med 1: 686-692, 1995.

25. Dalai I, Missiaglia E, Barbi S, et al: Low expression of ARHI is associated with shorter progression-free survival in pancreatic endocrine tumors. Neoplasia 9: 181-183, 2007. 